\title{
Necrotizing Soft Tissue Infections
}

\author{
Authors

\section{K. Anand Goud ${ }^{1}$, C.Naga Raghavendra Reddy ${ }^{2}$} \\ Corresponding Author
}

${ }^{1}$ Professor, Dept of Surgery, Mamata Medical College \& Hospital, Khammam., Telangana State, India ${ }^{2}$ Senior Resident, Dept of Surgery, Mamata Medical College \& Hospital, Khammam Telangana State, India

\section{K. Anand Goud}

Email:kagoudkmm@gmail.com

\begin{abstract}
Necrotizing soft tissue infections (NSTIs) rank among the more difficult disease processes encountered by physicians and surgeons, are aggressive infections that can result in severe disability or death. This study consist of 50 patients with necrotizing soft tissue infections were admitted to Mamata general hospital in Khammam, Telangana state during last 5 years period. Patients of both sexes aged between20-70 years are included in this study. NSTI is more prevalent in female and also common in old age patients suffering with diabetes. Risk factors include chronic disease like diabetes, lower extremity venous insufficiency, old age, obesity/ malnutrition, immunocompromised, alcoholism, drug abuse, pregnancy. NSTIs most commonly seen in the perineum, extremities, genitalia, with fewer arising on the chest or the abdomen. Most of infections are associated with bacterial infections and commonly isolated organism is streptococcus. The average time from initiation of symptoms to hospital admission was 5 days. Wound closure was begun as soon as the infection was controlled, and often was started early-2 to 4 days after initial debridement. Forty patients successfully achieved wound closure during initial hospitalization, an average of 27 days after initial debridement and ten patients were discharged from the hospital with open wounds, left to close by secondary intention. Early diagnosis, hospital admission and surgical debridement helps in treatment of disease and decreases the mortality rates.
\end{abstract}

Keywords- Necrotizing, soft tissue, infections, risk factors, fasciitis, mortality.

\section{Introduction}

Necrotizing soft tissue infections (NSTIs) rank among the more difficult disease processes encountered by physicians and surgeons. NSTIs can arise primarily in the dermis and epidermis, but they more commonly affect the deeper layers of adipose tissue, fascia, or muscle ${ }^{[1]}$. Necrotising soft tissue infections (NSTI) are aggressive infections that can result in severe disability or death. NSTI, formerly known as necrotising fasciitis, is an aggressive progressing bacterial infection that often results in severe morbidity (e.g. organ failure and amputation) and is associated with high mortality rates ${ }^{[2]}$. Some of the patients have co morbidities predisposing for NSTI ${ }^{[3]}$. The most common microbiological finding is mixed flora or group-A streptococcus infection ${ }^{[4]}$. The cornerstones in the treatment of NSTI are extensive surgery, general resuscitation and broadspectrum antibiotics. Furthermore, hyperbaric oxygenation therapy (HBO) and/or intravenous poly specific immunoglobulin G (IVIG) are used at many centres specialized in treating NSTI. The standard 
treatment consists of broad-spectrum antibiotics, wide surgical debridement, and supportive care. Most patients require multiple surgical debridements, and survivors often have large and complex wounds requiring soft tissue coverage and prolonged hospitalizations. Even with optimal treatment, NSTIs portend significant morbidity and have mortality rates of $25 \%-35 \%$ in recent series.

The aim of this study is to do a clinical study in the patients suffering with NSTI with respect to incidence, age wise and sex wise prevalence and place of occurrence, clinical parameters and isolation of causative agents.

\section{Materials and Methods}

This study consist of 50 patients with necrotizing soft tissue infections were admitted to Mamata general hospital in Khammam, Telangana state during last 5 years period after obtaining permission from hospital ethical committee. Patients were diagnosed and confirmed by either histologic examination or a combination of clinical, microbiologic, and gross anatomic findings. Each patient's history was collected to determine preexisting illnesses, admitting symptoms, admission physical findings, site of origin of the necrotizing infection, extent and depth of spread, and microbiology of the initial wound cultures. All the patients were examined and relavent samples were collected and sent for the laboratory. Standard treatment after admission included cardiovascular stabilization and assessment of extent of infection. Broad-spectrum antibiotics were administered to cover gram-positive cocci, gram-negative enteric rods, and anaerobic flora. Patients were taken to the operating room expeditiously for aggressive debulking of infected tissue. All necrotic skin, subcutaneous tissue, fascia, and obviously nonviable muscle were removed and sent for microbiologic and histologic examination. Viable dermis and soft tissue were saved to aid later closure, even after undermining with dissection to remove all necroticfascia. The wounds were then dressed loosely with gauze moistened with saline. Antibiotics were adjusted based on wound culture and sensitivities. All the patients were monitored for a duration of one year and subsequent complications were recorded.

\section{Results}

This study is conducted at the Mamata general hospital it includes 50 patients of both sexes aged between20-70 years. Table1 describes about the patients demographic data. NSTI is more prevalent in female and also common in old age patients.

Table.1: Demographic data of patients

\begin{tabular}{|l|c|c|}
\hline Age(years) & $\begin{array}{c}\text { Males } \\
\text { No(\%) }\end{array}$ & $\begin{array}{c}\text { Females } \\
\text { No(\%) }\end{array}$ \\
\hline $20-30$ & 0 & $1(2)$ \\
\hline $30-40$ & $1(2)$ & $4(8)$ \\
\hline $40-50$ & $3(6)$ & $7(14)$ \\
\hline $60-70$ & $4(8)$ & $8(16)$ \\
\hline $70-80$ & $7(14)$ & $11(22)$ \\
\hline Total & $19(38)$ & $31(62)$ \\
\hline
\end{tabular}

The common sites for NSTI are perineum, trunk, extremities like legs, hands and also seen in any region of body. In this study common site for NSTI is perineum followed by extremities like legs. Anatomical distribution is given in table2.

Table 2: Anatomic distribution of NSTI

\begin{tabular}{|l|c|c|}
\hline Place of NSTI & No effected & percentage \\
\hline Trunk & 4 & 8 \\
\hline Perineum & 18 & 36 \\
\hline Extremities & 15 & 30 \\
\hline Multiple sites & 13 & 26 \\
\hline Total & 50 & 100 \\
\hline
\end{tabular}

Table 3.Risk factors associated with NSTI

\begin{tabular}{|l|c|c|}
\hline Risk factor & $\begin{array}{c}\text { No } \\
\text { effected }\end{array}$ & $\begin{array}{c}\text { Percentage } \\
(\mathbf{\%})\end{array}$ \\
\hline Diabetes mellitus & 14 & 28 \\
\hline Hypertension & 2 & 4 \\
\hline Malnutrition & 2 & 4 \\
\hline Intravenous drug abuse & 2 & 4 \\
\hline Obesity & 3 & 6 \\
\hline Heart disease & 2 & 4 \\
\hline Alcohol abuse & 7 & 14 \\
\hline Peripheral vascular disease & 6 & 12 \\
\hline HIV & 2 & 4 \\
\hline Hepatic disorders & 4 & 8 \\
\hline pregnancy & 1 & 2 \\
\hline Others & 5 & 10 \\
\hline Total & 50 & 100 \\
\hline
\end{tabular}

NSTI is associated with the many risk factors like Diabetes, hypertension, intravenous drug abuse etc. 
NSTI is more common in the diabetic patients and patients with peripheral vascular disease. Various risk factors were shown in table3.

The blood parameters and biochemical parameters were estimated in all the patients and mean \pm S.E were recorded (table.4). The C-reactive protein, WBC count, haemoglobin level, serum sodium level, serum creatinine level, and serum glucose level were increased in most of patients. Samples for the cultural examinations were collected aseptically from the patients and sent to the laboratory examination. Table 5 indicates the microbial agents responsible for the necrotizing infections

Table.4 Haemotological and biochemical factors of patients with NSTI

\begin{tabular}{|l|c|}
\hline Biochemical parameter & Mean \pm S.E \\
\hline C reactive protein $\mathrm{mg} / \mathrm{dL}$ & $160 \pm 2.1$ \\
\hline Systolic blood pressure $(\mathrm{mmHg})$ & $131 \pm 2.2$ \\
\hline Pulse rate $(\mathrm{bpm})$ & $110 \pm 5.6$ \\
\hline Temperature $(\mathrm{C})$ & $38.1 \pm 1.5$ \\
\hline Total leukocyte count per mm3 & $16.3 \pm 1.3$ \\
\hline Platelet count $(1000 / \mathrm{mm} 3)$ & $312 \pm 10.5$ \\
\hline Haemoglobin $\mathrm{g} / \mathrm{dl}$ & $10.2 \pm 0.6$ \\
\hline Albumin, serum $(\mathrm{g} / \mathrm{dL})$ & $2.2 \pm 0.2$ \\
\hline Urea nitrogen, serum $(\mathrm{mg} / \mathrm{dL})$ & $28.4 \pm 1.6$ \\
\hline Sodium mmol/L & 132.6 \\
\hline Creatinine mg/dL & $2.6 \pm 0.8$ \\
\hline Glucose $\mathrm{mg} / \mathrm{dL}$ & $260 \pm 12.5$ \\
\hline Bilirubin, total serum $(\mathrm{mg} / \mathrm{dL})$ & $1.5 \pm 0.2$ \\
\hline Calcium, serum $(\mathrm{mg} / \mathrm{dL})$ & $7.8 \pm 0.4$ \\
\hline
\end{tabular}

Table 5 Indicates the microbial agents responsible for the necrotizing infections

\begin{tabular}{|l|c|c|}
\hline Organisms isolated & $\begin{array}{c}\text { No } \\
\text { effected }\end{array}$ & $\begin{array}{c}\text { Percentage } \\
(\%)\end{array}$ \\
\hline Aerobic bacteria & & \\
\hline Streptococci & 6 & 12 \\
\hline Enterococci & 5 & 10 \\
\hline Staphylococci & 5 & 10 \\
\hline Escherichia coli & 4 & 8 \\
\hline Proteus species & 4 & 8 \\
\hline Anaerobic bacteria & & \\
\hline Peptostreptococci & 6 & 10 \\
\hline Bacteroidesspecies & 4 & 8 \\
\hline clostridialspecies & 3 & 6 \\
\hline Others & 7 & 14 \\
\hline Fungal species & 5 & 10 \\
\hline Idiopathic & 2 & 4 \\
\hline
\end{tabular}

Surgical treatment consist of early debridement's followed delayed reconstructive procedures. Wound closure was begun as soon as the infection was controlled, and often was started early-2 to 4 days after initial debridement. Forty patients successfully achieved wound closure during initial hospitalization, an average of 27 days after initial debridement and ten patients were discharged from the hospital with open wounds, left to close by secondary intention. Out of 10 , two patients died before wound closure and were suffering with diabetes and renal disease. Delay in the time between admission and first debridement significantly affects ultimate outcome. After an extended hospitalization, multiple dressing changes and surgical procedures, the survivor of NSTI faces months of continued physical therapy to regain functional independence.

\section{Discussion}

NSTI was first described by Hippocrates in the 5th century BC. He described it as a complication of acute streptococcal infection ${ }^{[5]}$. The first Englishlanguage descriptions of NSTIs were by the British surgeon Leonard Gillespie and British physicians Gilbert Blaine and Thomas Trotter in the late 18th century. The disease was known as phagedaenic ulcer, phagedena gangrenous, gangrenous ulcer, malignant ulcer, putrid ulcer, or hospital gangrene ${ }^{[6]}$ Necrotizing soft tissue infections represent a diverse collection of potentially lethal, rapidly progressive bacterial diseases. They share a histologic pattern of invasion of the subepithelial soft tissues by microorganisms, resulting in perivascular lymphocytic infiltrate, vascular thrombosis, tissue edema, and necrosis ${ }^{[7]}$. Additionally, they have a common strategy for treatment: resuscitation from shock, expeditious and repeated debridement of all necrotic tissue, wide-spectrum intravenous antibiotic coverage, and early hyper alimentation.

There is no age or gender predilection, but higher rates of NSTIs are seen in obese, diabetic, and immunocompromised patients, as well as alcoholics and patients with peripheral vascular disease. Risk factors include chronic disease like diabetes, lower extremity venous insufficiency, Age > 50 years, Obesity/ malnutrition, Immunocompromised host, Alcoholism, drug abuse, pregnancy.

NSTIs can occur in any area of the body but are most commonly seen in the extremities, perineum, 
and genitalia, with fewer arising on the chest or the abdomen ${ }^{[20]}$. The most common sites of necrotizing soft tissue infections were the perineal region (Fournier's gangrene, 36\%), foot ulcerations and infections (30\% of patients), and traumatic wounds (14\% of patients).

Wall and colleagues found that a white blood cell (WBC) count $<15,000$ cells $/ \mathrm{mm} 3$ and a serum sodium level greater than $135 \mathrm{mmol} / \mathrm{L}$ had a negative predictive value of $99 \%$ and a $90 \%$ sensitivity for detecting NSTIs ${ }^{[7]-[8]}$. The LRINEC, developed based on data from 89 consecutive patients with NSTI compared with 314 patients with severe cellulitis or abscess or both, stratifies patients based on level of C-reactive protein, WBC count, hemoglobin level, serum sodium level, serum creatinine level, and serum glucose level at admission . Scores $\geq 6$ were found to have a $92 \%$ positive predictive value and a $96 \%$ negative predictive value ${ }^{[9]}$.

The nonspecific inflammatory signs of pain, swelling, and erythema occurred most commonly in all patients, whereas the most specific signs, crepitus and blistering, existed in $54 \%$ of patients. Soft tissue as detected by plain or computed tomography occurred in 27 patients, thus these three signs serve asa helpful screening profile. However, almost $20 \%$ of patients with such infections do not possess any of these three signs, making it imperative that the treating clinician pursue other means of achieving diagnostic certainty when a high level of clinical suspicion exists. Symptoms like pain, edema and erythema expressed by the patients correlate well with previous reports ${ }^{[10]}$. Crepitus and radiographic evidence of soft tissue air, although very suggestive of an anaerobic necrotizing process, "do not occur frequently enough to afford sufficient negative predictive value in their absence. However, the combination of crepitus blistering, and soft tissue air seen on radiography can serve as a useful screening triad ${ }^{[10]}$.

The average time from initiation of symptoms to hospital admission was 5 days. The cornerstone of appropriate treatment for NSTIs is early and wide surgical debridement. Increased time from admission to debridement and inadequacy of initial debridement have repeatedly been associated with increased mortality ${ }^{[11]}$.

Even from the earliest reports of the disease, it has been repeatedly observed that early surgical fasciotomy and debridement is essential to an efficient, effective treatment ${ }^{[12]}$. Delay of more than 12 hours to initial debridement has been associated with increased number of surgical debridement's and a higher incidence of septic shock and acute renal failure ${ }^{[13]}$.

Wound healing obstacles that often complicate but are not unique to NSTIs include local factors such as wound infection, wound necrosis, repeated trauma, and tissue hypoperfusion. Systemic factors such as chronic illnesses and malnutrition must also be addressed ${ }^{[10]}$

Necrotizing soft tissue infections arising from certain locations were more likely to result in death than others. In particular, infections arising from perineal sources predisposed patients to death ${ }^{[14]}$. Other significantly lethal sites of origin included burn wounds, perforated intra-abdominal viscera (usually colon), and dermal infections associated with the Group A beta-hemolytic streptococcal toxic shock syndrome (Strep TSS). Diabetes mellitus was the most common pre-existing medical condition present in admitted patients; when the conditions of diabetes, acute renal failure, and age greater than 60 years were combined, the mortality rate increased remarkably. Other premorbid medical diagnoses that influenced mortality included cardiac disease, carcinoma, malnutrition, intravenous drug abuse, and pulmonary disease. Mortality was related to failure to provide expeditious debridement $(80 \%$ of patients had a delay in diagnosis and first surgery), paucity of pathognomonic physical signs (only $20 \%$ of patients demonstrated either crepitus or radiographic air in the soft tissues), and large number of organs failed on admission ${ }^{[15]-[18]}$.

\section{Conclusion}

NSTI is an increasingly common problem, early diagnosis of the presence of a NSTI is essential for proper outcomes and are often characterized by progressive and potentially fatal soft tissue infection that requires prompt, radical, and often multiple 
surgical debridement of all involved tissue with rational antibiotic treatment.

\section{Acknowledgement}

Authors acknowledge the immense help received from Mamata medical college, the scholars whose articles are cited and included in references of this manuscript. The authors are also grateful to authors/editors/publishers of all those articles, journals and books from where the literature for this article has been reviewed and discussed.

\section{References}

1. Timo W. Hakkarainen, Nicole M. Kopari, Tarn N. Pham and Heather L. Evans,Necrotizing soft tissue infections: Review and current concepts in treatment, systems of care, and outcomes.CurrProbl Surg. 2014 Aug; 51(8): 344-362.

2. Hasham S, Matteucci P, Stanley PRW et al. Necrotising fasciitis. BMJ2005;330:830-832

3. Bernal NP, Latenser BA, Born JM et al. Trends in necrotizing acute softtissue infection patients 2000-2008. Burns 2012;38:252-60.

4. Morgan MS. Diagnosis and management of necrotic singfasciitis: amultipara metric approach. J Hosp Infect 2010;75:249-57.

5. Descamps V, Aitken J, Lee M. Hippocrates on necrotizing fasciitis. Lancet. 1994; 344: 556.

6. Loudon I. Necrotizing fasciitis, hospital gangrene, and phagedena. Lancet. 1994;344:1416-141.

7. Wall D, Kleain S, Black S, de Virgilio C. A simple model to help distinguish necrotizing from non-necrotizing soft-tissue infections. J Am Coll Surg. 2000;191(3):227-231.

8. Wall D, de Virgilio C, Black S, Klein S. Objective criteria may assist in distinguishing necrotizing fasciitis from nonnecrotizingsift-tissue infections. Am J Surg. 2000;179(1):17-21.

9. Wong C, Khin L, Heng K, Tan K, Low C. The LRINEC (laboratory risk indicator for necrotising fasciitis) score: a tool for distinguishing necrotising fasciitis from other soft-tissue infections. Crit Care Med. 2004;32(7):1535-1541.

10. Miller L, Carrick M, Scott B, Hodges J, Pham H. Necrotizing fasciitis caused by community-associated methicillin-resistant Staphylococcal aureus in Los Angeles. N Engl J Med. 2005;352(14):1445-1453.

11. Shiroff A, Herlitz G, Gracias V. Necrotizing soft tissue infections. J Intensive Care Med. 2014;29(3):138-144

12. McHenry C, Piotrowski J, Petrinic D, Malangoni M. Determinants of mortality for necrotizing soft-tissue infections. Ann Surg. 1995;221:558-565.

13. Kobayashi L, Konstantinidis A, Shackelford $S$, et al. Necrotizing soft tissue infections: delayed surgical treatment is associated with increased number of surgical debridements and morbidity [internet]. J Trauma. 2011; 71(5):1400-1405.

14. Baskin LS, Carroll PR. Cattolica EV, et al. Necrotising soft tissue infectionsOf the perineum and genitalia. Br J Urol 1990; 65:524-529.

15. Clayton MD, Fowler JE, Sharifi R, et al. Causes, presentation andsurvival of fiftyseven patients with necrotizing fasciitis of the malegenitalia. SurgGynecolObstet 1990; 170:49-55.

16. Ward RG, Walsh MD. Necrotizing fasciitis: 10 years experienceina district general hospital. Br J Surg 1991; 78:488-489.

17. Patino JF, Castro D. Necrotizing lesions ofsoft tissues: a review. WorldJ Surg 1991; 15:235-239.

18. David C. Elliott, Joseph A. Kufera and Roy A. M. Myers. Necrotizing Soft Tissue Infections Risk Factors for Mortality and Strategies for Management. Annals of surgery 1996, Vol. 224, No. 5, 672-683. 